\title{
Meiose e viabilidade polínica em acessos de Capsicum annuum e Capsicum baccatum
}

\author{
Meiosis and pollen viability in accessions of Capsicum annuum and Capsicum baccatum
}

\author{
Kellen Coutinho Martins ${ }^{I^{*}}$ Telma Nair Santana Pereira ${ }^{\mathrm{I}}$ Sérgio Alessandro Machado Souza ${ }^{\mathrm{I}}$ \\ Fabiane Rabelo da Costa ${ }^{\mathrm{I}}$
}

\section{RESUMO}

O objetivo deste trabalho foi estudar o comportamento meiótico e a viabilidade polínica em quatro acessos das espécies Capsicum annuum e Capsicum baccatum. Em todos os acessos, foram observados 12 bivalentes, confirmando o número e nível de ploidia relatados na literatura para essas espécies. Os resultados mostraram uma divisão celular normal, porém algumas anormalidades foram detectadas, tais como migração precoce dos cromossomos em metáfases I e II, cromossomos retardatários em anáfase I e divisão assincrônica. Os acessos estudados apresentaram um índice meiótico variando de 75,6 a 93,6\%, e a viabilidade polínica em todos os acessos foi superior a 90\%, demonstrando que as irregularidades meióticas observadas não comprometeram a viabilidade destes.

Palavras-chave: pimentas, irregularidades meióticas, grão de pólen, índice meiótico.

\section{ABSTRACT}

The objective of this research was to study the meiotic behavior and pollen viability in four accessions of species Capsicum annuum and Capsicum baccatum. In all accessions, twelve bivalents were observed, confirming the number and ploidy level reported in the literature for these species. The results showed a normal cell division although some abnormalities had been detected, as early chromosome migration at metaphases I and II, later chromosomes at anaphase I and asynchronous division. The studied accessions presented a meiotic index (MI) that varied from 75.6 to $93.6 \%$ and the pollen viability in all accessions was higher than $90 \%$, demonstrating that the meiotic irregularities observed didn't affect their viability.

Key words: peppers, meiotic irregularities, pollen grain, meiotic index.

\section{INTRODUÇÃO}

O gênero Capsicum é composto por 31 espécies, sendo cinco domesticadas e as demais classificadas como semidomesticadas e silvestres. Dentro do gênero, as espécies podem ser distintas, de acordo com o número básico de cromossomos, em dois grupos: um $\operatorname{com} n=x=12$ e o outro grupo $\operatorname{com} n=x=13$ cromossomos (MOSCONE et al. 2007). Estudos sobre número de cromossomos e nível de ploidia, análises sobre o comportamento cromossômico de híbridos $\mathrm{F}_{1}$ e aspectos referentes à hibridação interespecífica entre espécies cultivadas e silvestres são importantes, pois podem auxiliar programas de melhoramento em termos de direcionamento de cruzamentos mais promissores e introgressão de genes.

As espécies que compõem o gênero Capsicum estão distribuídas em três complexos gênicos distintos com base na cruzabilidade. O complexo $\boldsymbol{C}$. annuum reúne as espécies $C$. annuum, $C$. chinense e C. frutescens; o complexo $\boldsymbol{C}$. baccatum reúne $\boldsymbol{C}$. baccatum var. baccatum (forma silvestre) e $\boldsymbol{C}$. baccatum var. pendulum (forma cultivada); e o complexo $C$. pubescens reúne algumas espécies silvestres e apenas uma cultivada, C. pubescens (PICKERSGILL, 1991). O sucesso de obtenção de híbridos interespecíficos ocorre quando cruzamentos são realizados entre espécies do mesmo complexo, embora o emprego de técnicas de resgate de embrião

'Laboratório de Melhoramento Genético Vegetal, Universidade Estadual do Norte Fluminense Darcy Ribeiro (UENF), 28013-602, Campos dos Goytacazes, RJ, Brasil. E-mail: kellen.coutinho@hotmail.com. *Autor para correspondência. 
tenha permitido a obtenção de híbridos entre espécies pertencentes a complexos gênicos diferentes, como é o caso do híbrido $\mathrm{F}_{1}$ entre $\boldsymbol{C}$. annuum e $\boldsymbol{C}$. baccatum (YOON et al., 2006).

Espécies silvestres são consideradas repositórios de genes e, via hibridação interespecífica, têm permitido o melhoramento de muitas variedades modernas de culturas agronomicamente importantes (HAJJAR \& HODGKIN, 2007). Entretanto, considerando o grande número de espécies em coleções de germoplasma, o emprego destas em programas de melhoramento genético ainda é incipiente e isso se deve provavelmente à existência de barreiras pré e pós-fertilização.

O conhecimento da fertilidade das espécies envolvidas num programa de hibridação interespecífica é importante para que o melhorista tenha chance de ser bem-sucedido nos cruzamentos a serem realizados. A fertilidade de uma espécie, que regra geral é medida via viabilidade polínica, é consequência da formação de gametas normais e balanceados. Segundo DEFANISCOARIZE et al. (1995), o sucesso da hibridação, tanto intra quanto interespecífica, em termos genéticos, também é determinada por uma meiose regular, para que resulte na formação de gametas viáveis.

Considerando a falta de conhecimento sobre a fertilidade de espécies mantidas em coleções de germoplasma para posterior uso em programas de melhoramento, via hibridação interespecífica, o presente estudo foi realizado com os objetivos de avaliar o comportamento meiótico e estimar a viabilidade polínica de quatro acessos de Capsicum representantes de espécies cultivadas e semidomesticadas.

\section{MATERIAL E MÉTODOS}

Foram utilizados dois acessos representantes da espécie domesticada Capsicum annuum var. annuum (UENF 1503 - pimenta e UENF 1562 - pimentão) e dois acessos representantes das espécies semidomesticadas Capsicum annuum var. glabriusculum (UENF 1559) e Capsicum baccatum var. baccatum (UENF 1495). Esses acessos foram caracterizados morfoagronomicamente e molecularmente por SUDRÉ et al. (2006) e por COSTA et al. (2006), respectivamente.

Sementes desses materiais foram germinadas em copos plásticos de $500 \mathrm{ml}$ e posteriormente transferidas para vasos, sendo mantidos 10 vasos por acesso, em casa de vegetação, sob condições recomendadas para a cultura.
Durante o período de floração, botões florais de diferentes tamanhos e em diferentes estádios de desenvolvimento foram coletados e fixados em solução de etanol: ácido acético, na proporção de $3: 1$, por $24 \mathrm{~h}$. Em seguida, foram transferidos para uma solução de álcool $70 \%$ e conservados em geladeira até serem utilizados. Para o preparo das lâminas, três anteras por botão floral por indivíduo, de cada acesso estudado, foram maceradas (squash) sobre a lâmina em gotas de carmim acético $1 \%$.

Para a estimativa do índice meiótico (IM), conforme LOVE (1951), botões florais na antese foram coletados em solução de etanol $70 \%$ e conservados na geladeira. As lâminas, cinco por acesso, foram preparadas a partir da técnica de esmagamento (squash), em que anteras foram maceradas e coradas em carmim acético $1 \%$. Tétrade com quatro células de mesmo tamanho foi considerada normal e qualquer desvio (mônade, díade, tríade e políade) foi considerado anormal. Sob microscópio óptico foram contados 1.500 produtos pós-meióticos para cada acesso.

A viabilidade polínica dos acessos foi estimada via coloração tripla de Alexander (ALEXANDER, 1969). Para tal, botões florais na antese foram coletados em solução de etanol $70 \%$ e conservados a $4^{\circ} \mathrm{C}$. Na preparação das lâminas, as anteras foram maceradas em uma gota do corante. Para cada acesso, foram feitas quatro lâminas por botão e em cada lâmina foram contados 400 grãos de pólen, perfazendo um total de 1.600 grãos de pólen. Todas as lâminas foram observadas sob microscópio óptico (Olympus BX60), e as imagens foram capturadas com o Image-Pro Plus Software (versão 5.1, Media Cybenertics).

\section{RESULTADOS E DISCUSSÃO}

A análise meiótica dos acessos permitiu observar 12 cromossomos em associação bivalente, em diacinese e metáfase I (Figura la e 1b, respectivamente), corroborando o que a literatura registra para essas espécies conhecidas como diploides, $\operatorname{com} 2 \mathrm{n}=2 \mathrm{x}=24$ cromossomos (POZZOBON et al., 2006; MOSCONE et al., 2007).

De um modo geral, a meiose das espécies estudadas foi predominantemente regular; no entanto, algumas irregularidades foram observadas, a migração precoce dos cromossomos, dos cromossomos retardatários e divisão assincrônica, ou seja, diferentes fases da meiose II em um mesmo núcleo, foi a mais comum.

O acesso UENF 1503 (C. annuum var. annuum - pimenta), de um total de 87 células em 


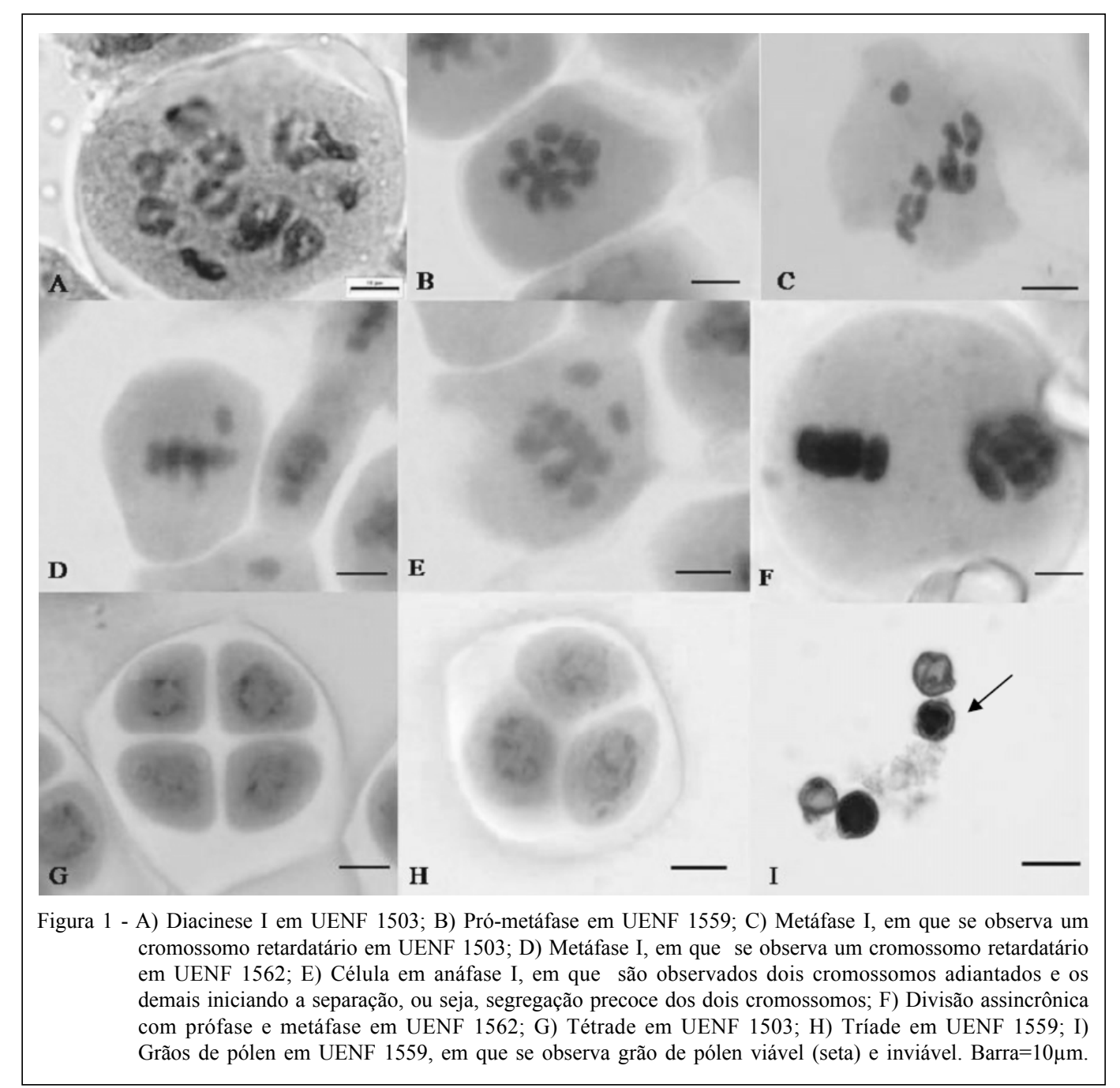

diacinese e metáfase I, apresentou 79,31\% das células com cromossomos em associações bivalentes normais (Figura 1a). O restante, 20,69\%, corresponde a células em metáfases I, com cromossomos retardatários. Cromossomos retardatários normalmente são perdidos durante a divisão celular, gerando células filhas aneuploides. Na metáfase II, anáfase e telófase I e II, os valores percentuais de células com cromossomos apresentando segregação irregular diminuíram, uma vez que $97,30 \%$ das células observadas segregaram normalmente, sugerindo que os cromossomos podem ter sido perdidos durante a meiose ou pode ter ocorrido o check point, que permite correções de falhas durante a meiose (WEINERT, 1998).

O acesso UENF 1562 apresentou 78,78\% das células em diacinese e metáfase I normais, em que foi possível observar os 12 bivalentes. Dentre as anormalidades meióticas observadas nesse acesso, $57,09 \%$ constituíram-se de cromossomos retardatários
(Figura 1d) e com segregação precoce (Figura 1e e Tabela 1). Essas anormalidades podem resultar em gametas desbalanceados ao final da divisão celular. De acordo com PAGLIARINI (2000), as anormalidades meióticas mais comuns observadas em diversas espécies é justamente a segregação cromossômica irregular, caracterizada pela migração precoce ou por cromossomos retardatários em metáfase I e em anáfase I. Verificou-se, ainda, a ocorrência de divisão assincrônica na meiose II, isto é, 21,05\% das células apresentando um dos seus grupos de cromossomos em prófase, enquanto o outro grupo encontrava-se em metáfase (Tabela 1 e Figura 1f).

O acesso UENF 1559 mostrou uma meiose, de um modo geral, regular, com $96,67 \%$ das células normais em diacinese e metáfase I. Observaram-se, também nesse acesso, divisões assincrônicas em 50\% das anormalidades meióticas (Tabela 1), com núcleos apresentando os cromossomos na placa metafásica e

Ciência Rural, v.40, n.8, ago, 2010. 
Tabela 1 - Porcentagem de irregularidades meióticas e comportamento pós-meiótico nos acessos UENF 1503, UENF 1562, UENF 1559 e UENF 1495.

\begin{tabular}{|c|c|c|c|c|}
\hline Anormalidades & 1503 & 1562 & 1559 & 1495 \\
\hline Cromossomos retardatários (metáfase I e II) & 94,74 & 36,85 & 44,44 & 0 \\
\hline Segregação precoce (anáfase I e II) & 5,26 & 21,05 & 0 & 0 \\
\hline Orientação da fibra do fuso & 0 & 21,05 & 11,12 & 0 \\
\hline Divisão assincrônica & 0 & 21,05 & 44,44 & 0 \\
\hline Número de células anormais & 19 & 19 & 18 & 0 \\
\hline Total de células analisadas & 124 & 90 & 415 & 36 \\
\hline$\%$ de Células anormais & 15,33 & 21,11 & 4,34 & 0 \\
\hline Índice Meiótico & 85,06 & 93,67 & 82,6 & 75,60 \\
\hline Viabilidade Polínica & 96,53 & 98,91 & 96,69 & 96,89 \\
\hline
\end{tabular}

\% VP: porcentagem de grãos de pólen viáveis; \% IM: porcentagem de tétrades normais.

no outro núcleo os cromossomos dispersos, o que, como consequência, deu origem à telófase II, apresentando três grupos de cromossomos ao invés de quatro (Figura 1h). Pelo fato de essa espécie ser semidomesticada e não ter sofrido uma pressão de seleção intensa, era esperado que, entre as espécies aqui analisadas, esta fosse apresentar um maior número de anomalias, porém um dos menores percentuais de células anormais foi observado na meiose desse acesso (Tabela 1).

O acesso UENF 1495, representante da espécie Capsicum baccatum var. baccatum, não apresentou nenhuma irregularidade durante a divisão meiótica. Além disso, foram observados os bivalentes em $100 \%$ das células analisadas em diacinese e metáfase I, confirmando o número de cromossomos e o nível de ploidia da espécie.

A orientação irregular do fuso na meiose II foi observada nos acessos UENF 1562 e UENF 1559, em $21,05 \%$ e $11,12 \%$ das células com anomalias, respectivamente (Tabela 1). De acordo com CAETANOPEREIRA et al. (1998), esse tipo de irregularidade é importante na meiose, pois, dependendo do tipo, os fusos podem unir ou separar os cromossomos homólogos.

Uma vez que o comportamento meiótico de uma planta está diretamente relacionado ao seu grau de fertilidade, as alterações observadas durante a divisão celular poderão refletir-se na viabilidade dos grãos de pólen (DEFANI-SCOARIZE et al., 1995). A ocorrência de falhas, como cromossomos retardatários ou desorganização dos fusos, pode ser indesejável, por exemplo, para a produção de híbridos, por imprigirem às novas gerações variações em função da perda ou do ganho de cromossomos, não desejadas na escolha dos parentais.
Irregularidades também foram observadas em outros estudos com espécies domesticadas de Capsicum, apesar do pareamento regular dos cromossomos (SOUZA et al., 2000; POZZOBON \& WITTMANN, 2006). Segundo PICOLI et al. (2003), as próprias condições de manejo das plantas também podem alterar a meiose, visto que situações de estresse interferem no metabolismo desses indivíduos.

Foi possível observar que, em todos os acessos estudados, a citocinese não foi simétrica, tendo ocorrido alguns produtos pós-meióticos do tipo tríade (Figura 1h). No entanto, houve predominância de tétrades normais, o que é esperado ao final de uma divisão meiótica normal, muito embora a ocorrência dessas tríades tenha resultado em um índice meiótico abaixo do valor esperado, especialmente no acesso cultivado, UENF 1503 (Tabela 1). Tríades podem ser originadas a partir de falhas ocorridas no momento da divisão do citoplasma durante a meiose I ou II e estão normalmente relacionadas com a formação de gametas não reduzidos, o que pode ser vantajoso para uma espécie, caso a poliploidia seja uma alternativa evolutiva (PICKERSGILL, 1977).

$\mathrm{O}$ índice meiótico (IM) dos quatro acessos estudados pode ser encontrado na tabela 1 . O acesso UENF 1562 apresentou o maior valor de IM (93,67\%), enquanto UENF 1495 apresentou o menor IM (75,60\%). Apesar de LOVE (1951) estabelecer que plantas com índices meióticos abaixo de $90 \%$ podem ter uso restrito no melhoramento, no presente estudo, os acessos apresentaram IM satisfatórios próximos de $90 \%$, o que pode ser verificado na viabilidade polínica, que foi alta.

A formação do grão de pólen segue dois padrões de citocinese, determinados pelo momento em que ela ocorre durante a meiose. Na citocinese simultânea, nenhuma parede é formada depois da meiose I (ESAU, 1977). Nesse caso, os micrósporos 
são arranjados em uma tétrade tetraédrica (HESSE et al., 2009), já na citocinese sucessiva uma parede é formada depois da primeira e da segunda divisão (SCHULZ \& JENSEN, 1968), levando à formação de vários tipos de tétrades (HESSE, 2009). Conforme pode ser observado na figura $1 \mathrm{~g}$, em Capsicum, prevalece a citocinese do tipo simultânea, e o arranjo das tétrades é do tipo tetragonal (ESAU, 1977).

Foi observada, nos acessos estudados, a ausência de sincronia durante a divisão celular, ou seja, diferentes fases da meiose em um mesmo botão floral. Esse comportamento tem sido reportado na literatura e está de acordo com o observado por PICOLI et al. (2003), que relataram a presença de diferentes fases da meiose numa mesma classe de botão, definindo seis classes de botão, baseadas na relação de tamanho entre cálice e corola, forma da margem do cálice e presença de pigmentos nas anteras. Destaca-se que, da classe 1 até a classe 5 , foram observadas as fases da meiose e, na classe 6 , só se encontram grãos de pólen.

A viabilidade polínica dos acessos variou de 96,53 a 98, 91\%, com predominância de grãos de pólen viáveis (Tabela 1, Figura 1i) em todos os acessos, observando-se assim uma correlação positiva entre o percentual de tétrades normais e a viabilidade dos grãos de pólen.

\section{CONCLUSÃO}

Os acessos estudados possuem um comportamento normal durante a microsporogênese, com alta formação de bivalentes e uma viabilidade polínica acima de $96 \%$, mostrando que, apesar de terem sido observadas algumas irregularidades meióticas, estas não foram suficientes para comprometer a fertilidade das espécies.

\section{REFERÊNCIAS}

ALEXANDER, M.P. Differential staining of aborted non aborted pollen. Stain Techonology, v.44, p.117-122, 1969. Disponível em: <http://www.informaworld.com/smpp/ content $\sim \mathrm{db}=\mathrm{all} \sim$ content $=\mathrm{a} 785954047>$. Acesso em: 28 ago. 2004. doi: 10.3109/10520296909063335.

CAETANO-PEREIRA, C.M. et al. Syncytes, abnormal cytokinesis and spindle irregularities in maize microsporogenesis. Maydica, v.43, p.235-252, 1998. Disponível em: <http:// cat.inist.fr/?aModele $=$ afficheN\&cpsidt $=1765206>$. Acesso em: 10 jun. 2007

COSTA, F.R. et al. Genetic diversity among Capsicum accessions using RAPD markers. Crop Breeding and Applied Biotecnology, v.6, p.18-23, 2006. Disponível em: < http:// www.sbmp.org.br/cbab/siscbab/uploads/bd6ba09c-4aa3b62a.pdf>. Acesso em: 12 ago. 2007.
DEFANI-SCOARIZE, M.A. et al. Evolution of meiotic behavior in double-cross maize hybrids and their parents. Maydica, v.40, n.1,2 p.319-324, 1995. Disponível em: <http://cat.inist.fr/ ?aModele $=$ afficheN\&cpsidt $=3007059>$. Acesso em: $10 \mathrm{jun}$. 2007.

ESAU, K. Anatomy of seed plants. 2.ed. USA: John Wiley \& Sons, 1977. 550p.

HAJJAR, R.; HODGKIN, T. The use of wild relatives in crop improvement: A survey of developments over the last 20 years. Euphytica, v.156, p.1-13, 2007. Disponível em: $<$ http:// www.springerlink.com/content/p122468633546675/>. Acesso em: 03 ago. 2007. doi: 10.1007/s10681-007-9363-0.

HESSE, M. et al. Pollen terminology. An illustrated handbook. Vienna: Springer, 2009. 264p.

LOVE, R.M. Varietal differences in meiotic chromosomes behavior of Brazilian wheats. Agronomy Journal, v.43, p.72-76, 1951. Disponível em: <http://agron.scijournals.org/cgi/reprint/43/2/ 72 ? maxtoshow $=\&$ hits $=10$ \&RESULTFORMAT $=$ \&author 1 $=$ Love $\% 2 \mathrm{C}+\mathrm{RM} \&$ title $=$ Varietal + differences + in + meiotic + chromoso mes+behavior + of + Brazilian + wheats \& andorexacttitle $=$ and $\&$ andorexacttitleabs $=$ and $\&$ andorexactfulltex $\mathrm{t}=\mathrm{and} \&$ searc hid=1\&FIRSTINDEX=0\&sortspec=relevance\&resourcetype=HWCIT>. Acesso em: 09 mar. 2006.

MOSCONE, E.A. et al. The evolution of chili peppers (Capsicum - Solanaceae): a cytogenetic perspective. vith international solanaceae conference. Acta Horticulturae, v.745, p.137-169, 2007. Disponível em: <http:// www.actahort.org/books/745/745_5.htm>. Acesso em: 10 nov. 2007.

PAGLIARINI, M.S. Meiotic behavior of economically important plant species: the relationship between fertility and male sterility. Genetics and Molecular Biology, v.23, p.997-1002, 2000. Disponível em: <http://www.scielo.br/scielo.php?pid=S141547572000000400045\&script=sci_arttext $>$. Acesso em: 07 jan. 2007. doi: $10.1590 / \mathrm{S} 1415-475 \overline{7} 2000000400045$.

PICKERSGILL, B. Cytogenetics and evolution of Capsicum L. In: TSUCHIYA, T.; GUPTA, P.K. Chromosome engineering in plants: genetics, breeding, evolution. Amsterdam: Elsevier, 1991. p.139-160. Disponível em: <http://www.cababstractsplus.org/ abstracts/Abstract.aspx?AcNo=19931636082>. Acesso em: 16 jun. 2005 .

PICKERSGILL, B. Chromosomes and evolution in Capsicum. In: POCHARD, E. (Ed.). Capsicum 77. Avignon-Montfavet, France: Institut National de la Recherche Agronomique, 1977. p.27-37. (Comptes Rendus 3ème Congrès Eucarpia Piment). Disponível em: <http://www.cababstractsplus.org/abstracts/ Abstract.aspx?AcNo=19931636082>. Acesso em: 16 jun. 2005.

PICOLI, E.A.T. et al Associação de fases meióticas e estádios dos micrósporos com características morfológicas de botões florais de pimentão. Ciência e Agrotecnologia, v.27, n.3, p.708-713, 2003. Disponível em: <http://www.editora.ufla.br/ revista/27_3/Vol27_03.htm $>$. Acesso em: 12 maio, 2005.

POZZOBON, M.T.; WITTMANN, M.T. A meiotic study of the wild and semi-domesticated Brazilian species of genus Capsicum L. (Solanaceae). Cytologia 71, v.3, p.275-287, 
2006. Disponível em: <http://www.jstage.jst.go.jp/article/ cytologia/71/3/71_275/_article>. Acesso em: 15 ago. 2007. doi: $10.1508 /$ cytologia. $\overline{7} 1.275$

POZZOBON, M.T. et al. Chromosome numbers in wild and semidomesticated Brazilian Capsicum L. (Solanaceae) species: do $\mathrm{x}=12$ and $\mathrm{x}=13$ represent two evolutionary lines? Botanical Journal Linnean Society, v.151, p. 259-269, 2006. Disponível em: <http://www3.interscience.wiley.com/ journal/118580681/abstract?CRETRY $=1 \&$ SRETRY $=0>$ Acesso em: 22 set. 2007. doi: 10.1111/j.10958339.2006.00503.x

SCHULZ, S.R.; JENSEN, W.A. Capsella embryogenesis: the egg, zygote, and young embryo. American Journal of Botany, v.55, p.807-819, 1968. Disponível em: <http://www.jstor.org/ pss/2440969>. Acesso em: 14 mar. 2007.

SOUZA, M.M. et al. Irregularidade meiótica em pimenta. In: CONGRESSO BRASILEIRO DE OLERICULTURA, 40., 2000, São Pedro, SP. Horticultura Brasileira. Brasília: Sociedade de Olericultura do Brasil, 2000. V.18. p.748-749.
SUDRÉ, C.P. et al. Variáveis multicategóricas na determinação da divergência genética entre acessos de pimenta e pimentão. Horticultura Brasileira, v.24, p.88-93, 2006. Disponível em: <www.scielo.br/pdf/hb/v24n1/a18v24n1.pdf>. Acesso em: 24 mar. 2007. doi: 10.1590/S0102-05362006000100018

YOON, J.B. et al. Overcoming two postfertilization genetic barries in interespecific hibridization between Capsicum annuum and $\boldsymbol{C}$. baccatum for introgression of Antracnose Resistance. Breeding Science, v.56, p.31-38, 2006. Disponível em: < http://www.jstage.jst.go.jp/article/jsbbs/56/1/56_31/_article>. Acesso em: 15 jan. 2007. doi: 10.1270/jsbbs.56.31.

WEINERT, T. DNA damage checkpoints update: getting molecular. Current Opinion in Genetics \& Development, v.8, p.185193, 1998. Disponível em: <http://www.sciencedirect.com/ science?_ob=ArticleURL\&_udi=B6VS0-45MFJBD$50 \&$ user $=686212 \&$ coverDate $=04 \% 2$ F $30 \% 2$ F $1998 \&$ rdoc $=1 \&$ fmt $=$ high\&_orig $=$ search\&_sort $=\mathrm{d} \&$ _docanchor $=\&$ vie $\mathrm{w}=\mathrm{c} \&$ searchStrId $=1233488002 \&$ rerunOrigin $=$ google \&_acct $=$ C $000037219 \&$ \&_version $=1 \&$ \&urlVersion $=$ $0 \&$ userid $=686212 \& \mathrm{md} 5=\mathrm{d} 40 \overline{1} 85 \mathrm{ba} 6 \mathrm{c} 2 \mathrm{e} 5 \mathrm{af} 5 \mathrm{efe} \overline{\mathrm{c}} \mathrm{c} 52837165 \mathrm{a} 3 \mathrm{e}>$ Acesso em: 08 abr. 2006. doi: 10.1016/S0959-437X(98)80140-8. 